\title{
Investigation of Kinesiophobia, State and Trait Anxiety Levels in Patients with Lower Extremity Ligament Injury or Fracture History
}

\section{Alt Ekstremitede Bă̆ Yaralanması veya Kırık Geçmişi Olan Bireylerde Kinezyofobi, Durumluluk ve Sürekli Kaygı Düzeylerinin İncelenmesi}

\author{
Begümhan Turhan, Günseli Usgu, Serkan Usgu, Murat Ali Çınar, Elif Dinler, Deniz Kocamaz \\ Physiotherapy and Rehabilitation Department, Hasan Kalyoncu University, Gaziantep, Turkey
}

\begin{abstract}
B. Turhan
0000-0003-0842-2059

G. Usgu

0000-0003-4269-5210

S. Usgu

0000-0002-4820-9490

M. A. Cinar

0000-0003-2122-3759

E. Dinler

0000-0003-0198-1456

D. Kocamaz

0000-0002-0611-7686

Geliş Tarihi/Date Received: 03.10.2018

Kabul Tarihi/Date Accepted: 18.12.2018

Yayin Tarihi/Published Online 22.04.2019

Yazışma Adresi /

Corresponding Author:

Begumhan Turhan

Hasan Kalyoncu Üniversitesi, Fizyoterapi Ve Rehabilitasyon Bölümü, Gaziantep, Turkey E-mail:

begum.aliosmanoglu@hku.edu.tr
\end{abstract}

C02019 Türkiye Spor Hekimleri Derneği. Tüm hakları saklıdır.

\section{ABSTRACT}

Objective: Kinesiophobia and fear to return to activity are common problems encountered following musculoskeletal injuries. The relationship between kinesiophobia and some psychological parameters has been investigated in the individuals with a history of ligament injury or fracture of lower extremity.

Material and method: The study included 120 individuals (60 female, 60 male), 40 individuals with a history of ligament injury, 40 individuals with a history of fractures in the lower extremities and 40 healthy individuals. The participants were evaluated with Tampa Scale of Kinesiophobia (TSK) and the State and Trait Anxiety Inventory (STAI I\&STAI-II). Number of fractures or ligament injuries, time of injury, time elapsed from the diagnosis and the duration of treatment were noted.

Results: There were no significant differences between the groups in terms of STAI-I and STAI-II scores $(p>0.05)$, however there were significant differences between groups in terms of TSK scores $(p=0.001)$. There were no correlation between STAI-I and TSK scores and STAI-II and TSK scores ( $p>0.05)$. TSK scores of the individuals with a history of fracture were significantly higher than other groups $(p=0.007)$. There were no significant differences between the TSK scores in terms of fracture location and ligament injury $(p>0.05)$.

Conclusion: It has been concluded that kinesiophobia was not related to emotional status and anxiety levels. Higher kinesiophobia scores of the individuals who had fractures could be related to longer periods of treatment.

Key words: Trauma, ligament injury, fracture, kinesiophobia, anxiety

\section{ÖZ}

Amaç: Kinezyofobi ve aktiviteye dönüş korkusu kas-iskelet sistemi yaralanmalarının ardından sık görülen sorunlardandır. Alt ekstremitede bağ yaralanması ya da kırık öyküsü olan bireylerde kinezyofobi ile bazı psikolojik parametrelerin ilişkisi incelenmiştir.

Gereç ve Yönemler: Çalışmaya, alt ekstremitede bağ yaralanması öyküsü olan 40 kişi, alt ekstremitede kırık öyküsü olan 40 kişi ve sağlıklı bireylerden oluşan 40 kişi olmak üzere 120 kiși (60 kadın, 60 erkek) dahil edildi. Çalışmaya katılan bireyler Tampa Kinezyofobi Ölçeği (TKÖ), Durumluluk ve Sürekli Kaygı Ölçeği (STAI-I ve STAI-II) ile değerlendirildi. Katılımcıların travma bölgesi, tanısı, travma sonrası yaşanan problemler ve uygulanan tedaviler, tedavi süreleri not edildi.

Bulgular: Bireylerin STAI-I ve STAI-II değerlerinde gruplar arası anlamlı fark bulunmamış ( $p>0.05)$, ancak TKÖ skorları arasında anlamlı farklar olduğu görülmüştür $(p=0.001)$. 
Bireylerin STAI-I ve TKÖ skorları arasında, STAI-II ve TKÖ skorları arasında da anlamlı ilişki bulunmamıştır ( $p>0.05)$.Kırık geçmişi olan bireylerin TKÖ skorlarının diğer gruplardaki TKÖ skorlarına göre anlamlı düzeyde yüksek olduğu görülmüştür ( $p=0.007)$. Kırık ve bağ yaralanma bölgesine göre değerlendirildiğinde TKÖ skorları arasında anlamlı farklılık bulunmamıştır ( $p>0.05)$.

Sonuç: Kinezyofobinin duygusal durum ve kaygı düzeyleri ile ilgili olmadığı sonucuna ulaşılmıştır. Kırık öyküsü olan bireylerin kinezyofobi skorlarının anlamlı düzeyde yüksek olması kırık sonrası tedavi süresinin uzun olması ile açıklanabilir.

Anahtar sözcükler: Travma, bağ yaralanması, kırık, kinezyofobi, anksiyete

Available at: http://journalofsportsmedicine.org and http://dx.doi.org/10.5152/tjsm.2019.130

Cite this article as: Turhan B, Usgu G, Usgu S et al. Investigation of kinesiophobia, State and Trait Anxiety levels in patients with lower extremity ligament injury or fracture history. Turk J Sports Med. 2019;54(3):175-82.

\section{GíRiş}

Yaralanmalar veya ağrılı durumlar sonucunda, problemin tekrar etmesi korkusu ile fiziksel hareket ve aktiviteden aşırı kaçınma durumu "kinezyofobi" olarak tanımlanmaktadır $(1,2)$. Kinezyofobi, beynin farklı alanlarını içeren özellikle de limbik sistem yapılarından olan amigdala ve insula bölgesi ile bağlantılıdır (3). Kori ve ark., kinezyofobiyi yaralanmaya karşı duyarlılık ve kırılganlık inancından kaynaklanan olumsuz etkilere sahip hareket ve aktivite korkusu olarak tanımlamışlardır (4). Hareket ve aktivite korkusu kavramlarının yanı sıra, yeniden yaralanma korkusu kavramının da kinezyofobi ile aynı anlamda kullanıldığı görülmüştür (5).

Hayatta kalmanın temel mekanizmalarından biri olan korku, doğuştan gelen veya öğrenilen duygusal tepkileri kapsamaktadır. Kazanılan (öğrenilen) korku, acı ya da ağrı tehdidi gibi daha önceden deneyimlenen bir uyarana tepki olarak kaçma ve kaçınma özellikli davranışları tetikler. Hem öğrenilen hem de doğuştan gelen korku yanitları, beynin temporal lobunda bulunan ve birkaç subkortikal çekirdekten oluşan amigdala kompleksi tarafından kontrol edilmektedir (6). Amigdala ve insula bölgeleri başta korku olmak üzere duygular, hafıza ve sağkalım ile ilgili dürtülerin denetiminden sorumlu anatomik bölgeler olarak bilinmektedir (7).

Kinezyofobi ile ilgili daha çok bel ağrılı hastalarda yapılmış çalışmalara rastlanılmaktadır $(8,9)$. Ön çapraz bağ ameliyatı geçiren hastalarda, tibia ve fibula kırıkları sonrasında, diz bölgesine ait artroskopik yaklaşımlar ve alt ekstremite yaralanmaları sonrasında görülen kinezyofobiyi değerlendiren çeşitli çalışmalar da bulunmaktadır (10-15). Yapılan çalışmalar bağ yaralanması geçirmiş kişilerin sağlıklı bireylere göre daha yüksek kinezyofobiye sahip olduklarını ortaya koymuştur $(11,13)$. Kırık görülen vakalarda da kırığın neden olduğu, başta ağrı olmak üzere, çeşitli komplikasyonların hareketten kaçınma davranışına neden olduğu belirtilmiştir (12). Bağ yaralanması veya kırık geçirilmiş olması daha önceden kötü deneyimlenen durumlar olarak hafıza kayıtlarına geçebilmektedir. Kötü deneyimler bireylerde hareket etme ve yeniden yaralanma korkusuna neden olabilir ve aktiviteden kaçınma eğilimi yaratabilir.

Bağ yaralanmaları ve kırık sonrası kinezyofobi değerlerini karşılaştırarak inceleyen bir çalışmaya rastlanılmamıştır. Bu çalışmada alt ekstremitede bă̆ yaralanması ya da kırık öyküsü olan bireylerde kinezyofobi ve anksiyete düzeylerini değerlendirilerek karşılaştırmak ve kinezyofobinin bazı parametreler ile olan ilişkilerini incelemek amaçlanmıştır.

\section{YÖNTEM}

Çalışmaya, en az 6 ay önce alt ekstremitede bağ yaralanması geçirmiş olan 40, alt ekstremitede kırık öyküsü olan 40 ve sağlıklı bireylerden oluşan 40 kişi olmak üzere toplam 120 kişi (60 kadın, 60 erkek) katıldı. Herhangi bir kronik hastalığ (diyabetus mellitus, hipertansiyon, tiroid hastalıkları, kronik böbrek yetmezliği vb) olanlar, vücut kitle indeksi (BMI) $\geq 30$ olanlar, geriatrik gruba dahil olan bireyler, fonksiyonel 
bağımsızlık ölçeğinden tam puan alamayan bireyler çalışmaya dahil edilmedi. Çalıșmaya katılan bireyler Tampa Kinezyofobi Ölçeği (TKÖ) ve Durumluluk ve Sürekli Kaygı Ölçeği (STAI-I ve STAI-II) ve Fonksiyonel Bağımsızlık Ölçeği (FBÖ) ile değerlendirildi. Kinezyofobi değerlendirmesinde, Türkçe geçerlilik ve güvenilirliğini Yılmaz ve ark.'nın yapmıș olduğu TKÖ anketi (16), anksiyete ve kaygı durumu değerlendirmesinde Öner'in Türkçe'ye uyarladığı STAI-I ve STAI-II envanteri (17), fonksiyonel durum ve günlük yaşam aktivitelerinin belirlenmesinde ise Küçükdeveci ve ark.'nın Türkçe'ye uyarladığı Fonksiyonel Bağımsızlık Ölçeği (FBÖ) kullanıldı (18).

TKÖ kas iskelet sistemi ile ilişkili sağlık problemlerinde kullanılan 17 soruluk bir ölçektir; puanlama 17 ile 68 arasında yapılmaktadır. Alınan puanın yüksekliği kinezyofobisinin de yüksek olduğunu göstermektedir (8).

STAI-I ve STAI-II envanterleri toplam yirmişer maddeden oluşan iki ayrı ölçekten meydana gelmektedir. Çalışmamızda bu envanterler, alt ekstremite yaralanma öyküsü olan kişilerin durumluluk ve sürekli kaygı düzeylerini ölçmek için kullanılmıştır.

FBÖ, kendine bakım, sfinkter kontrolü, hareket, mobilite, iletişim ve sosyal iletişim bölümlerinden oluşan 18 maddelik bir ölçektir; puanlama 18 ile 126 arasında yapılmaktadır. Ölçekten alınan puanın yüksekliği bireyin fonksiyonel olarak bağımsızlığa yaklaştığını gösterir.

Katılımcıların yaş, cinsiyet, dominant taraf, boy, kilo bilgileri sorguland, kırık ve bağ yara- lanması öyküsü alındı, yaralanma bölgesi, tanı üzerinden geçen süre ve uygulanan tedaviler (immobilizasyon, ilaç kullanımı, fizyoterapi ve rehabilitasyon, cerrahi ve diğer) ve tedavi süreleri not edildi. Bu çalışma için Hasan Kalyoncu Üniversitesi Girişimsel Olmayan Araştırmalar Etik Kurulu'ndan onay alındı (Karar no: 20169).

\section{İstatistiksel Analiz}

Çalışmanın istatistiksel analizleri SPSS 21.0 paket programı kullanılarak yapıldı. Değișkenlerin normal dağılıma uygunluğu Shapiro-Wilk testi ile incelendi. Ölçülebilen veriler aritmetik ortalama \pm standart sapma olarak verildi. Frekans dağılımları n (\%) olarak ifade edildi. Grup içi ve gruplar arasındaki farklılıklar Tek Yönlü Varyans Analizi (ANOVA) ile karşılaştırıldı. Gruplar arasındaki farkı belirleyebilmek için post hoc testlerden GamesHowell kullanıldı, p değeri $<0.05$ olarak alındı. Veriler arasındaki ilişkiler Pearson Momentler Çarpımı korelasyon testi ile belirlendi.

\section{BULGULAR}

Günlük yaşamında herhangi bir fonksiyonel kısitlılığı olmayan ve FBÖ skorlarından tam puan (126 puan) alan katılımcıların yaş, cinsiyet, beden kitle indeksi (BKI), dominant taraf ile ilgili tanımlayıcı bulguları Tablo 1'de verilmiştir. Tüm bireylerin ortalama yaşı $25.69 \pm 7.47$, BKI $23.65 \pm 4.06$ 'dır. Tüm katılımcıların $\% 50$ 'si kadın, $\%$ 50'si erkek ve \% 82.5'inin dominant tarafının sağ, \%17.5'inin ise sol taraf olduğu belirlenmiştir. Gruplar arasında dominant taraf dışında anlamlı fark bulunmamıştır.

Tablo 1. Tanımlayıcı bulgular

\begin{tabular}{lllllll}
\hline & Yaş (Yıl) & BKİ & \multicolumn{2}{l}{ Dominant Taraf } & \multicolumn{2}{l}{ Cinsiyet } \\
\cline { 2 - 7 } & & & Sağ & Sol & Kadın & Erkek \\
K & $26.32 \pm 8.35$ & $25.22 \pm 4.76$ & $33(\% 82.5)$ & $7(\% 17.5)$ & $16(\% 40)$ & $24(\% 60)$ \\
B & $27.52 \pm 8.00$ & $22.90 \pm 3.65$ & $29(\% 72.5)$ & $11(\% 27.5)$ & $22(\% 55)$ & $18(\% 45)$ \\
S & $23.22 \pm 5.13$ & $22.82 \pm 3.24$ & $37(\% 92.5)$ & $3(\% 7.5)$ & $22(\% 55)$ & $18(\% 45)$ \\
P değeri & 0,28 & 0,063 & $0.010 *$ & & 0,307 & \\
\hline
\end{tabular}

K: Kırık geçmişi, B: Bağ yaralanması geçmişi, S: Sağlıklı birey, BKí: Beden kitle indeksi Yaş ve BKİ değerleri ortala

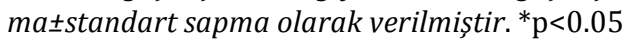


Çalışmaya katılan bireylerde, bağ yaralanması (Şekil-1) ve kırığın en sık görüldüğü bölgelerin ayak ve ayak bileği bölgesi olduğu belirlenmiştir (Şekil-2).

\section{Bağ Yaralanması Bölgeleri}

ayak ve ayak bileği $\quad$ krus $\quad$ diz

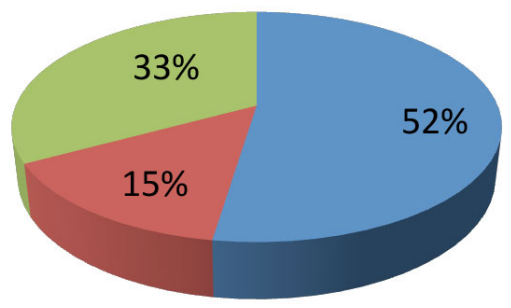

Şekil 1: Bă̆ yaralanması görülen bölgelerin dağılımı

\section{Kırık Bölgeleri}

ayak ve ayak bileği $\quad$ krus $\quad$ diz $\quad$ uyluk

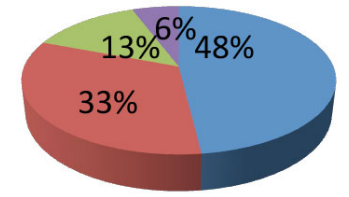

Şekil 2: Kırık görülen bölgelerin dağılımı
Kırık ya da bağ yaralanması geçirenlerle sağlıklı gruptaki bireylerin TKÖ skorları, STAI-I durumluluk ve STAI-II sürekli kaygı skorları Tablo 2 'de verilmektedir.

3 grup karşılaştırıldığında STAI-I ve STAI-II değerleri arasında istatistiksel olarak anlamlı bir fark bulunmamış ( $p>0.05)$, ancak kinezyofobi skorlarında gruplar arasındaki farkın anlamlı olduğu görülmüştür ( $\mathrm{p}<0.05)$. Kırık geçmişi olan bireylerin kinezyofobi skorları diğer gruplardaki bireylerin skorlarından yüksek bulunmuştur.

Sağlıklı grup ile bağ yaralanması geçmişi olan grup arasında TKÖ skorları açısından anlamlı fark bulunmaktadır ( $\mathrm{p}=0.021)$. Bağ yaralanması geçmişi olan grubun TKÖ skorları sağlıklı grubun TKÖ skorlarına göre anlamlı düzeyde yüksektir. Kırık geçmiși olan grubun TKÖ skorları sağlıklı grubun skorlarına göre anlamlı düzeyde yüksek bulunmuştur ( $\mathrm{p}=0.007)$. Kırık ya da bağ yaralanması geçmişi olan grupların TKÖ skorları karşılaştırıldığında, skorlar kırık geçmişi olan grubun lehine anlamlı düzeyde yüksektir $(\mathrm{p}=0.001)$.

Bireylerin STAI-I ve TKÖ skorları ile, STAI-II ve TKÖ skorları arasında korelasyon yoktur $(\mathrm{p}=0.37)$. Bireylerin TKÖ skorları ile yaş, BKİ, cinsiyet ve dominant tarafları arasında bir ilişki bulunmamıştır $(\mathrm{p}=0.29)$.

Tablo 2. Grupların TKÖ, STAI-I ve STAI-II skorlarının karşılaştırılması

\begin{tabular}{llll}
\hline & TKÖ değeri & STAI-I değeri & STAI-II değeri \\
\hline K & $42.62 \pm 7.91$ & $40.27 \pm 5.75$ & $45.35 \pm 4.96$ \\
Min-Max & $31-60$ & $32-55$ & $37-57$ \\
B & $38.05 \pm 7.06$ & $41.20 \pm 5.63$ & $45.17 \pm 6.08$ \\
Min-Max & $24-55$ & $32-56$ & $35-63$ \\
S & $30.80 \pm 4.17$ & $40.70 \pm 6.76$ & $44.57 \pm 4.33$ \\
Min-Max & $23-39$ & $24-53$ & $38-60$ \\
p değeri & $0.001^{*}$ & .793 & .782 \\
\hline
\end{tabular}

K: Kırık geçmişi, B: Bağ yaralanması geçmişi, S: Sağlıklı birey, TKÖ: Tampa Kinezyofobi Ölçeği, STAI-I\&STAI-II: Durumluluk ve Sürekli Kaygı Ölçeği. Değerler ortalama standart sapma olarak verilmiștir. ${ }^{*} \mathrm{p}<0.05$ 
Tedavi süreleri açısından değerlendirildiğinde, kırık vakalarının tedavi süresinin bağ yaralanması geçiren bireylerin tedavi sürelerine göre istatistiksel olarak anlamlı düzeyde yüksek olduğu görülmüştür $(\mathrm{p}=0.042)$. Yaralanma üzerinden geçen süre açısından bağ yaralanması ve kırık görülen olgularda gruplararası anlaml fark görülmemektedir $(p>0.05)$. Bireylerin tedavi sürelerinin ortalama değerlerinin ve yaralanma üzerinden geçen sürelerin ortalama değerlerinin gruplar arası karşılaştırılması Tablo 3'te verilmiștir.

Tablo 3. Kırık ve bağ yaralanması sonrası tedavi süreleri ile yaralanma üzerinden geçen sürelerin karşılaştırılması

\begin{tabular}{llll}
\hline & Ortalama & Min-Max & P değeri \\
\hline Kırık sonrası tedavi süresi (gün) & $51.62 \pm 14.51$ & $24-120$ & $.042^{*}$ \\
Bağ yaralanması sonrası tedavi süresi (gün) & $26.10 \pm 17.74$ & $7-90$ & .890 \\
Kırık tanısı üzerinden geçen süre (yıl) & $8.67 \pm 5.23$ & $1-25$ & $1-20$ \\
Bağ yaralanması tanısı üzerinden geçen süre (yıl) & $7.22 \pm 2.71$ & & \\
\hline
\end{tabular}

Değerler ortalama \pm standart sapma olarak verilmiștir.* $\mathrm{p}<0.05$

Kırık sonrası olgularda en yüksek TKÖ skorunun ayak ve ayak bileği bölgesi kırıklarında olduğu görülmüştür. Kırık bölgesine göre TKÖ skorları arasında anlamlı farklılık bulunmamaktadır ( $p>0.05)$. Aynı şekilde yaralanma bölgelerine göre STAI-I ve STAI-II skorları arasında da anlamlı farklılık görülmemiștir ( $\mathrm{p}>0.05)$. Bağ yaralanması sonrası olgularda en yüksek TKÖ skorunun diz bölgesi yaralanmaları sonrası olduğu görülmüștür. Yaralanma bölgesine göre
TKÖ, STAI-I ve STAI-II skorları incelendiğinde bölgeler arasında fark bulunmamıştır ( $\mathrm{p}>0.05)$. Skorlar Tablo 4'te verilmiştir.

Bireylerin yaşamları boyunca geçirdikleri bağ yaralanması sayısı ile TKÖ skorları ve kırık sayısı ile TKÖ skorları arasında istatistiksel olarak anlamlı ilişki bulunmamıştır $(\mathrm{p}=0.13)$. Yaralanma sonrası uygulanan tedaviler ve yüzdelik dağılımları Tablo 5'te verilmişir.

Tablo 4: TKÖ, STAI I ve STAI II skorlarının yaralanma bölgelerine göre incelenmesi

\begin{tabular}{lllllll}
\hline Kırık bölgesi & TKÖ skoru & $\boldsymbol{p}$ değeri & STAI I & $\boldsymbol{p}$ değeri & STAI II & $\boldsymbol{p}$ değeri \\
\hline Uyluk & $41.10 \pm 1.40$ & .944 & $36.75 \pm 2.82$ & .999 & $45.50 \pm 4.96$ & .654 \\
Diz & $43.91 \pm 6.17$ & .607 & $37.91 \pm 6.11$ & .966 & $45.08 \pm 4.04$ & .973 \\
Bacak & $39.88 \pm 2.64$ & .965 & $40.66 \pm 4.72$ & .665 & $44.16 \pm 3.84$ & .989 \\
Ayak ve ayak bileği & $47.75 \pm 7.00$ & .623 & $41.00 \pm 5.22$ & .961 & $45.77 \pm 5.18$ & .994 \\
\hline Bağ yaralanma bölgesi & & & & & & \\
\hline Diz & $39.28 \pm 4.49$ & .912 & $39.40 \pm 7.35$ & .802 & $46.07 \pm 7.61$ & .587 \\
Bacak & $38.66 \pm 4.70$ & .992 & $44.50 \pm 5.35$ & .914 & $44.21 \pm 4.41$ & .553 \\
Ayak ve ayak bileği & $37.04 \pm 6.67$ & .726 & $40.45 \pm 5.85$ & .999 & $44.35 \pm 5.23$ & .830 \\
\hline
\end{tabular}

TKÖ: Tampa Kinezyofobi Ölçeği, STAI-I\&STAI-II: Durumluluk ve Sürekli Kaygı Ölçeği. Değerler ortalama standart sapma olarak verilmiștir. ${ }^{*} \mathrm{p}<0.05$ 
Tablo 5: Travma sonrası uygulanan tedaviler

\begin{tabular}{lllll}
\hline Uygulanan tedaviler & $\mathbf{B}$ & & $\mathbf{K}$ & \\
\cline { 2 - 5 } & $\mathbf{N}$ & $\mathbf{0}$ & $\mathbf{N}$ & $\mathbf{\%}$ \\
İmmobilizasyon & 31 & $\% 77.5$ & 37 & $\% 92.5$ \\
İlaç & 10 & $\% 25$ & 8 & $\% 20$ \\
Fizyoterapi ve rehabilitasyon & 13 & $\% 32.5$ & 5 & $\% 12.5$ \\
Cerrahi & 3 & $\% 7.5$ & 2 & $\% 5$ \\
\hline B: Bağ yaralanması geçmişi, K: Kirlk geçmiși & & &
\end{tabular}

\section{TARTIȘMA}

Tampa skorlarının 37'den büyük olması kinezyofobinin yüksek olduğunu göstermektedir $(8,19)$. Çalışmamıza katılan bağ yaralanması ve kırık öyküsü olan tüm bireylerin ortalama kinezyofobi skorları yüksek düzeyde kinezyofobileri olduğunu göstermektedir. Bağ yaralanması ve kırık geçmiși olan katılımcıların tamamının kinezyofobi skorlarının sağlık bireylere göre yüksek düzeyde olması, travma geçiren bireylerin kötü deneyimlerinin hareket korkusuna neden olduğunu düşündürmektedir.

Goldberg ve ark.'nın yaralanma türü dikkate alınmaksızın yapmış oldukları bir çalışmada, yaralanma bölgesine göre kinezyofobi düzeyleri değerlendirilmiş, alt ekstremite yaralanmaları olan kişilerin kinezyofobi skor ortalaması $23.9 \pm 7.0$ olarak hesaplanmıştır. Üst ekstremite, omurga ve çoklu yaralanmaların da incelendiği çalışmada en düşük kinezyofobi değeri alt ekstremite yaralanmalarında görülmüştür. Aynı çalışmada bölgeler arası kinezyofobi skorlarında anlamlı bir fark görülmemiştir (20). Bu çalışmada da kırık ve bağ yaralanması sonrası kinezyofobi değerlerinde bölgeler arasında anlamlı fark görülmemiştir. Bu sonuç kinezyofobinin yaralanma bölgesi ile değil, yaralanma sonrası tedavi yöntemleri ve travmanın başka özellikleri ile ilgili olabileceğini düşündürmektedir.

Olsen ve ark., kaburga kırıkları sonrası cerrahi geçiren bireylerde fonksiyonel kapasite, fiziksel aktivite düzeyi ve omuz fonksiyonları azalırken, ağrı ve kinezyofobinin arttığını bulmuşlardır (21). Kırık olgularında kırığın neden olduğu, başta ağrı olmak üzere çeşitli komplikasyonların hareketten kaçınma davranışına neden olduğu bulunmuştur (12). Bu çalıșmada da kırık öyküsü olan bireylerde kinezyofobi skorlarının yüksek olduğu görülmüștür. Kırık sonrası TKÖ skorlarının bağ yaralanması sonrası TKÖ skorlarına göre anlamlı düzeyde yüksek olması, kırık sonrası tedavi sürelerinin bağ yaralanması sonrası tedavi sürelerine göre anlamlı düzeyde yüksek olması ile açıklanabilir.

Bazı çalışmalarda yaralanmaya bağlı hareket korkusunun uzamış hastalık süreci, geç iyileşme ve hastanede uzun süre kalma ile ilişkisi olduğu vurgulanmaktadır $(22,23)$.

Archer ve ark. ortopedik travmalarda tedavi süresinin uzamasının depresyon düzeylerini arttırdığını belirtmişlerdir (24). Depresyonda olan bireylerin yaralanma öncesi aktivite düzeyine dönememelerine neden olan faktörler arasında psikolojik tepkiler ve bunların yol açtığı fonksiyonel bozukluklardan bahsedilmektedir (25). Goldberg ve ark. kinezyofobi skorları yüksek olan kişilerin fiziksel ve ruhsal iyilik hallerinin düşük olduğunu belirlemişlerdir (20). Bunun yanı sıra, Kaçoğlu ve ark. yaptıkları çalışmada yaralanma sonrası depresyon ve kinezyofobi düzeylerini incelemişler, depresyon skorları ve kinezyofobi düzeyleri arasında korelasyon bulamamışlardır (26). Lundberg ve ark. kinezyofobi ile kas-iskelet sistemine ait ağrı şiddeti, fonksiyonel kısıtlılık ve psikolojik özellikler arasında ilişki bulunduğunu ifade ederken 
(27), Misterska ve ark. psikoloji ve ağrı ile ilişkili klinik verilerin kinezyofobinin belirleyicileri olmadığını iddia etmektedirler (28). Erden ve ark. diz osteoartritli bireylerde yaptıkları çalışmada kinezyofobi ve anksiyete arasında pozitif yönde kuvvetli bir korelasyon bulmuşlardır (29). Depresyon, anksiyete düzeyleri ile kinezyofobi düzeylerini inceleyen çeşitli çalışmaların farklı sonuçları olmakla birlikte, bu çalışmada gruplararası STAI-I ve STAI-II sonuçları arasında anlamlı fark bulunmaması tüm grupların benzer kaygı düzeylerine sahip oldukları, bu çalışmanın katılımcıları için kinezyofobinin durumluluk ve kaygı düzeyleriyle ilişkili olmadığı șeklinde yorumlanabilir. TKÖ skorlarının çeșitli faktörlerden etkilenebileceği düşünülmektedir.

Kinezyofobinin fonksiyonel durum ile de ilişkisi olduğunu öne süren çalışmalar bulunmaktadır $(23,30)$. Bu çalışmaya katılan tüm bireyler fonksiyonel olarak tam bağımsız olan öğrenciler ve üniversite çalışanlarından oluşmaktadır, dolayısıyla travmaya bağlı hareket korkusu nedenleri arasında fonksiyonel engellilik bulunmamaktadır.

Çalışmamızın en önemli kısıtlılığı unutma faktörünün göz ardı edilmesi ve hasta beyanlarına göre yapılmış olmasıdır. Cinsiyet ayrımı yapılmaksızın oluşturulan örneklem, kadın ve erkek arasında görülebilecek olası farkların ortaya konmasına engel olmuștur. Cinsiyet farklılıklarını inceleyen çalışmaların yapılması yararlı olacaktır. Ayrıca, tedavi öncesi ve tedavi sonrası kinezyofobi skorlarının incelendiği bir çalışma tedavi ve rehabilitasyon yöntemlerinin geliştirilmesine de ışık tutacaktır.

\section{SONUC}

$\mathrm{Bu}$ çalışmada kinezyofobinin kişilerin duygusal durum ve kaygı düzeyleri ile ilgili olmadığ görülmüştür. Kinezyofobi skorlarının kırık sonrası tedavi süreleriyle ilgili olabileceği gibi, uzun tedavi sürecinin yarattığı travmanın da hastada hareket korkusuna yol açabileceği düşünülmüştür. Doktor, fizyoterapist ve rehabilitasyon ekibinin diğer üyeleri tarafından kinezyofobi ve anksiyete durumunun dikkate alınması rehabilitasyon süreçlerini olumlu etki- leyebilir. Kinezyofobiye yönelik yaklaşımın rehabilitasyon programlarına eklenmesi için kinezyofobiye neden olan faktörlerin belirlenmesi gerekir.

\section{KAYNAKLAR}

1. Bingül ÖÖ, Aslan UB. Korku-Kaçınma İnanışlar Anketi'nin Türkçe'ye uyarlanması, güvenirliği ve geçerliği. Turk J Phys Med Rehab. 2013;24(1):135-43.

2. Slade PD, Troup JDG, Lethem J, et al. The fear-avoidance model of exaggerated pain perception-II: Preliminary studies of coping strategies for pain. Behav Res Ther. 1983;21(4):409-16.

3. Meier ML, Stämpfli P, Vrana A, et al. Neural correlates of fear of movement in patients with chronic low back pain vs. pain-free individuals. Front Hum Neurosci. 2016;386(10):1-9.

4. Kori SH, Miller RP, Todd DD. Kinesiophobia: a new view of chronic pain behavior. Pain Res Manag. 1990;3:3543.

5. Kvist J, Ek A, Sporrstedt K, et al. Fear of re-injury: a hindrance for returning to sports after anterior cruciate ligament reconstruction. Knee Surg Sports Traumatol Arthrosc. 2005;13:393-7.

6. Riccio A, Li Y, Moon J, et al. Essential role for TRPC5 in amygdala function and fear-related behavior. Cell. 2009;137(4):761-72.

7. Phelps EA, O'Connor KJ, Gatenby JC, et al. Activation of the left amygdala to a cognitive representation of fear. Nature neuroscience. 2001;4(4):437.

8. Vlaeyen JW, Kole-Snijders AM, Boeren RG, et al. Fear of movement/(re) injury in chronic low back pain and its relation to behavioral performance.Pain. 1995;62(3):363-72.

9. Vlaeyen JWS, Linton SJ. Fear-avoidance and its consequences in chronic musculoskeletal pain: A state of the art. Pain. 2000;85:317-32.

10. Feigenbaum LA, Baraga M, Kaplan LD, et al. Return to sport following surgery for a complicated tibia and fibula fracture in a collegiate women's soccer player with a low level of kinesiophobia. Int J Sports Phys Ther. 2015;10(1):95.

11. Jamshidi AA, Kamali M, Akbari M, et al. The effect of functional tests on kinesiophobia in anterior cruciate ligament-deficient patients with similar quadriceps strength to healthy controls. J Mod Rehab. 2016;10(2):67-73.

12. Sengül Y, Unver B, Karatosun V, et al. Assessment of pain-related fear in patients with the thrust plate prosthesis (TPP): Due to hip fracture and hip osteoarthritis. Arch Gerontol Geriatr. 2011;53(2):24952.

13. Flanigan DC, Everhart JS, Pedroza A, et al. Fear of reinjury (kinesiophobia) and persistent knee symptoms are common factors for lack of return to sport after anterior cruciate ligament reconstruction. Arthroscopy. 2013;29(8):1322-29. 
14. Levy B, O'Malley M, Krych A, et al. Revision Multiligament Knee Reconstruction: Treatment Algorithm and Outcomes. Arthroscopy. 2017;33(6): e8-e9.

15. Chmielewski TL, Jones D, Day T, et al. The association of pain and fear of movement/reinjury with function during anterior cruciate ligament reconstruction rehabilitation. J Orthop Sports Phys Ther. 2008;38(12):746-53.

16. Yilmaz ÖT, Yakut Y, Uygur F, et al. Tampa Kinezyofobi Ölçeği'nin Türkçe versiyonu ve test-tekrar test güvenirliği. Turk J Phys Med Rehab. 2011;22(1):44-49.

17. Öner N. Türkiye'de Kullanılan Psikolojik Testler. İstanbul: Boğaziçi Yayınları; 1994.

18. Küçükdeveci AA, Yavuzer G, Elhan AH, et al. Adaptation of the functional independence measure for use in Turkey. Clin Rehabil. 2001;15:311-8.

19. Bränström H, Fahlström M. Kinesiophobia in patients with chronic musculoskeletal pain: differences between men and women. J Rehabil Med. 2008;40(5):375-80.

20. Goldberg P, Zeppieri G, Bialosky J, et al. Kinesiophobia and its association with health-related quality of life across injury locations. Arch Phys Med Rehabil. 2018;99(1):43-48.

21. Olsén MF, Slobo M, Klarin L, et al. Physical function and pain after surgical or conservative management of multiple rib fractures-a follow-up study. Scand J Trauma Resusc Emerg Med. 2016;24(1):128.

22. Sgroi MI, Willebrand M, Ekselius L, et al. Fearavoidance in Recovered Burn Patients: Association with Psychological and Somatic Symptoms. J Health Psychol. 2005;10:491-502.

23. Özkal Ö, Topuz S, Konan A, et al. Alt ekstremite yanık yaralanması olan bireylerde ağrı, kinezyofobi ve fonksiyonellik arasındaki ilişkinin incelenmesi. Ankara Eğt Arş Hast Derg. 2017;50 (3):122-28.

24. Archer KR, Abraham CM, Obremskey WT. Psychosocial factors predict pain and physical health after lower extremity trauma.Clin Orthop Relat Res. 2015;473(11):3519-26.

25. Richmond TS, Amsterdam JD, Guo W, et al. The effect of post-injury depression on return to pre-injury function: a prospective cohort study. Psychol Med. 2009;39:170920.

26. Kacoglu C, Atalay E, Turhan B. Assessing the kinesiophobia and depression status at return to sport following sport related injuries in physically contact and non-contact sports. Turk J Sports Med. 2018;53:6775

27. Lundberg MK. Various aspects of moving with musculoskeletal pain. Department of Orthopaedics Institute of Clinical Sciences PhD thesis. Göteborg: The Sahlgrenska Academy at Göteborg University; 2006.

28. Misterska E, Jankowski R, Głowacki J, et al. Kinesiophobia in pre-operative patients with cervical discopathy and coexisting degenerative changes in relation to pain-related variables, psychological state and sports activity. Med Sci Monit. 2015;21:181-94.

29. Erden A, Altuğ F, Malkoç A, et al. Diz osteoartritli bireylerde kinezyofobi, ağrı şiddeti, anksiyetedepresyon durumu ve yașam kalitesinin incelenmesi. OTSHD. 2016;7:1-17.

30. Thompson DP, Moula K, Woby SR. Are fear of movement, self-efficacy beliefs and fear of falling associated with levels of disability in people with osteoarthritis of the knee? A cross sectional study. Musculoskeletal care. 2017;15(3):257-62. 